\title{
Investment Timing and Capacity Choice under Uncertainty
}

\author{
Xiumei Lv, Shiqin Xu, and Xiaoling Tang \\ School of Finance, Chongqing Technology and Business University, Chongqing 400067, China \\ Correspondence should be addressed to Xiumei Lv; lvxium@126.com \\ Received 10 January 2014; Revised 22 February 2014; Accepted 23 February 2014; Published 27 March 2014 \\ Academic Editor: Qun Lin
}

Copyright (C) 2014 Xiumei Lv et al. This is an open access article distributed under the Creative Commons Attribution License, which permits unrestricted use, distribution, and reproduction in any medium, provided the original work is properly cited.

\begin{abstract}
This paper examines strategic investment between two firms that compete not only for investment timing but also for capacity under stochastic market demand. The value functions of real option for the follower, the dominant leader, and the preemptive leader are derived and their investment decisions are investigated. It finds that both firms will delay investment and the delayed margin of the follower will surpass that of the leader under greater uncertainty. Furthermore, both firms will provide more outputs in the face of increasing uncertainty and the growth rate of the follower's capacity will exceed that of the leader's. In addition, this paper finds that the follower will end up with a larger capacity than the leader.
\end{abstract}

\section{Introduction}

In the traditional theory, investment decision is analyzed by the net present value (NPV) method. However, the method cannot reflect uncertainty existing in the investment process effectively. Furthermore, when making decision, NPV is mechanical and passive since there are only two choices: invest now or never. Considering the uncertain, irreversible, and flexible feature of investment, the real option approach sees investment opportunity as an American option and is proper to deal with investment problem in the real world (see [1-4]).

As a matter of fact, investment strategies will be influenced and restricted with each other, so the value of the investment project depends not only on the company's own decision but also on the reaction of its competitors. The option game approach, the combination of real option with game theory, is elaborated by Smit and Trigeorgis [5]. Some literature applies the option game method to analyze investment problem under a duopoly or oligopoly market. Grenadier [6] develops an equilibrium framework for strategic option exercise games and provides an explanation for why some markets may experience building booms in the face of declining demand. Grenadier [7] provides a tractable approach for deriving equilibrium investment strategies in a continuous-time Cournot-Nash framework and obtains the impact of competition drastically eroding the value of the option to wait and lead to investment at near the zero net present value threshold. Chu and Sing [8] consider the subgame equilibrium strategies for a duopoly real option model with asymmetric demand functions and find that the relative strength of the firms has significant impact on the firms equilibrium strategies. Kong and Kwok [9] examine strategic investment games between two firms which compete for optimal investment under uncertain revenue flows in a duopoly market with negative externality and positive externality.

One common character of the above option game is that they assume a given investment output and are usually only concerned with the choice of investment opportunities. However, in reality, the scale of investment is an important factor that drives a person's decision-making. For example, real estate developers should choose the construction area to be explored and firms should decide the output quantity. Due to the uncertainty in the investment process, improper choice of investment opportunities or capacity will bring about great risks. In order to control risks, this paper investigates a real option model and applies option game method to analyze the investment timing and capacity choice problem under stochastic market environment.

There are still some literature considering the question of investment capacity. Wang and Zhou [10] derive closedform solutions for an equilibrium real options exercise model under stochastic revenues and costs for oligopoly 
and competitive markets with different production capacities. Aguerrevere [11] studies the effects of competitive interactions on investment decisions and on the dynamics of the price of a nonstorable commodity in a model of incremental investment with time to build and operating flexibility. Yang and Zhou [12] extends Dangl [13] to a duopoly in which one of the firms is the incumbent and the other firm is the entrant. Novy-Marx [14] analyzes the optimal investment decisions of heterogeneous firms in a competitive and uncertain environment and shows that in the competitive equilibrium real option premia remains significant. Comparing these papers with ours, the main difference and contribution are that our work analyzes the influence of capacity choice and obtains many interest conclusions. For example, previous literature usually predicts that the leader is better off by providing a larger capacity than his rival, while this paper proves that the first mover enters with a smaller capacity than the second mover and sheds light on why firm lacks incentive to pursue a large capacity preemption in an uncertain market.

This paper is divided into five sections. In Section 2, we lay out the model framework. Section 3 derives the value functions and investment thresholds when the firms serve as the follower, preemptive leader, and dominant leader. Section 4 explores a comparative static on the volatility of stochastic market demand. In Section 5, we draw a conclusion of this paper.

\section{Model Framework}

The model of this paper comes from the redevelopment investment problem of land in Capozza and $\mathrm{Li}$ [4]. In their paper, cash flow is uncertain in the whole investment process and satisfies Algebra Brown Motion. When investor makes his investment strategy, he must consider not only the investment timing but also the investment scale while the latter is reflected by intensity. What is different from Capozza and $\mathrm{Li}[4]$ is that this paper deals with investment problem in a duopoly market and uses product capacity to reflect each investor's scale. For these two firms, they must decide when to enter the market and what capacity they should produce.

Suppose that both firms are rational, risk-neutral, and profit-maximizing. The model adopts riskless interest rate $r$ to discount their payoff. Furthermore, two firms can provide unstorable commodity, the price of which is related to the market supply. Specially, we assume that the price $P(t)$ at time $t$ satisfies the following simple inverse demand function:

$$
P(t)=X(t)-\gamma Q
$$

where $X(t)$ is the exogenous market demand shock, $Q$ is the total market supply, and nonnegative parameter $\gamma$ is the slope of the linear demand function and is used to reflect the price sensitivity to the supply. From (1) we know that the increase or decrease of the total market supply will cause the price to rise or fall. Furthermore, function (1) indicates that the change of the market demand $X$ will be reflected on inverse demand curve. Since the variable changes unpredictably, we suppose that it is stochastic and evolves as a geometric Brownian motion

$$
d X(t)=\mu X d t+\sigma X d Z(t)
$$

where $\mu$ is a given positive constant and denotes the expected growth of $X, \sigma$ represents the volatility of the market demand, and $d Z$ is an increment of a standard Wiener motion and denotes the resource of uncertainty. Furthermore, (2) means that investors only know the current level of the market demand while the future level meets with a lognormal distribution. Therefore, $\ln X$ increases at a certain growth rate and is disturbed by a normally distributed random variable. In addition, to guarantee that the option is exercised within a finite period of time, we assume that $r>\mu$.

Each firm has only one chance to invest. As long as the investment opportunity exists, the firm has to consider when to take action and what capacity to provide. Suppose that the investment sunk cost is governed by the relation $C(Q)=k Q$, where $k$ is a nonnegative parameter. Hence, the investment cost will increase with their capacity choice.

In the existing literature, there are two types of investment. One is lumpy investment, such as Mason and Weeds [15], Besanko et al. [16], and Nishihara and Fukushima [17]; the other is incremental investment, such as Pindyck [3], Aguerrevere [11], and Novy-Marx [14]. In the lumpy investment, investment scale is decided at the investment time and all commodities are provided into the market for one time. In the incremental investment, commodities can be increased by an infinitesimal amount and the initial investment scale is expanded in the investment process. BarIlan and Strange [18] make a comparison with these two types. Pindyck [3] points out that incremental investment is an extreme case of lumpy investment and can be calculated conveniently. Therefore, this paper adopts lumpy investment to analyze capacity choice problem under uncertainty; that is to say, investor can adjust his output flexibly according to the external uncertainty in the environment while all products are supplied into the market the moment he exercises his option.

\section{Investment Problem in an Duopoly Market}

In this section, we will discuss strategic and competitive investment problem in a duopoly market, where uncertainty is reflected on the stochastic market demand. Two firms have to decide not only their investment timing but also their optimal capacity. Competitive behavior will be discussed from two aspects. One is a dominant case and the other is a preemptive case. Namely, the leader is dominant in the game or preempts the market.

When the leader makes his decision, he must consider the possible strategy of the follower. For the dominant leader, the leadership may be determined by two situations. One is determined exogenously, in which the leader can choose his optimal investment timing and optimal capacity since he knows his competitor will be prone to be a follower. The other is determined endogenously, in which the leadership is obtained after intense competition since the firm does 
not have comparative advantage over his rival in the game. Denote the leader and the follower as $l$ and $f$, respectively.

Just as the standard method in dynamic programming, we will adopt inverse induction. Firstly, consider the value function of the follower. Secondly, consider the investment problem of the dominant leader. Thirdly, premeditate the value function of the preemptive leader. The value functions in the case where two firms take action simultaneously are just the same as the value of themselves to be a follower.

3.1. Follower. Since the leader has taken investment action, the follower can make his decision optimally. Denote the investment timing and capacity of the follower as $T_{f}^{*}$ and $q_{f}^{*}$, respectively. If his competitor $l$ enters the market with capacity $q_{l}$, the value function of the follower can be expressed as

$$
\begin{gathered}
F\left(X, q_{f}\right)=\max _{T_{f}^{*}} E_{t}\left\{\int_{T_{f}^{*}}^{\infty}\left[X(s)-\gamma\left(q_{l}+q_{f}\right)\right] e^{-r(s-t)} d s\right. \\
\left.-k e^{-r\left(T_{f}^{*}-t\right)}\right\} q_{f} .
\end{gathered}
$$

When the payoff of the firm is large enough; that is, $X$ surpasses his investment trigger $X_{f}^{*}$, the follower begins to exercise his option. Furthermore, the question to look for $X_{f}^{*}$ is equivalent to the maximization of the option value.

By dynamic programming, (3) can be translated into the following partial differential equation:

$$
\frac{1}{2} \sigma^{2} X^{2} \frac{\partial^{2} F(X)}{\partial X^{2}}+\mu X \frac{\partial F(X)}{\partial X}-r F(X)=0 .
$$

At the optimal trigger $X_{f}^{*}$, the value of the firm satisfies the value-matching condition

$$
F\left(X_{f}^{*}, q_{f}\right)=\frac{X_{f}^{*} q_{f}}{r-\mu}-\frac{\gamma\left(q_{l}+q_{f}\right) q_{f}}{r}-k q_{f}
$$

and the smooth-pasting condition

$$
\frac{\partial F\left(X_{f}^{*}, q_{f}\right)}{\partial X}=\frac{q_{f}}{r-\mu} .
$$

Solving (4) associated with conditions (5) and (6), we can obtain the follower's value function

$$
\begin{aligned}
& F\left(X, q_{f}\right) \\
& =\left\{\begin{array}{cc}
\frac{q_{f}}{\beta-1}\left(\frac{\gamma\left(q_{l}+q_{f}\right)}{r}+k\right) & \text { if } X<X_{f}^{*}\left(q_{l}, q_{f}\right), \\
\times\left(\frac{X}{X_{f}^{*}}\right)^{\beta}, & \text { if } X \geq X_{f}^{*}\left(q_{l}, q_{f}\right) \\
\frac{X q_{f}}{r-\mu}-\frac{\gamma\left(q_{l}+q_{f}\right) q_{f}}{r} &
\end{array}\right.
\end{aligned}
$$

and the optimal trigger of the follower

$$
X_{f}^{*}\left(q_{l}, q_{f}\right)=\frac{\beta(r-\mu)}{\beta-1}\left(\frac{\gamma\left(q_{l}+q_{f}\right)}{r}+k\right),
$$

where $\beta$ is the positive solution of

$$
\frac{1}{2} \sigma^{2} \beta(\beta-1)+\mu \beta-r=0 .
$$

Before the investment threshold is reached, the follower makes a preparation to enter the market, the investment opportunity which is similar to an American option in a monopoly market. After the investment trigger is reached, the payoff is equivalent to the net present value and the follower exercises his option immediately.

From (8), we know that the investment triggers of the two firms to be a follower are identical to each other. In other words, if both firms are prone to be a follower, each one has $1 / 2$ possibility to be successful.

At the time when the firm draws up his investment timing, he must consider the optimal capacity, which can be determined by the maximization of the intrinsic value. The intrinsic value represents the value of a perpetual warrant or option to invest in the project at any future date. From (3), the intrinsic value of the follower can be expressed by

$$
W_{f}(X)=\max _{q_{f}^{*}}\left[\frac{X(t)}{r-\mu} q_{f}-\frac{\gamma\left(q_{l}+q_{f}\right) q_{f}}{r}-k q_{f}\right] .
$$

Therefore, $W_{f}(X)$ must be governed by the first-order condition with respect to $q_{f}$;

$$
\frac{X(t)}{r-\mu}-\frac{\gamma\left(q_{l}+2 q_{f}^{*}\right)}{r}-k=0 .
$$

That is to say, when the current market demand is $X(t)$ and the leader's capacity is $q_{l}$, the optimal capacity of the follower meets with

$$
q_{f}^{*}\left(X, q_{l}\right)=\frac{1}{2}\left[\frac{r}{\gamma}\left(\frac{X}{r-\mu}-k\right)-q_{l}\right] .
$$

From (12), it is easy to know that the follower will consider providing more outputs when the total demand $X(t)$ is in a good state. The reasoning is clear: the price will also be high if the market demand is high. More commodities will bring about more profit. Combining (8) and (12), we obtain the optimal trigger and the capacity of the follower

$$
\begin{gathered}
X_{f}^{*}\left(q_{l}\right)=\frac{\beta \gamma(r-\mu)}{r(\beta-2)}\left[q_{l}+\frac{k r}{\gamma}\right], \\
q_{f}^{*}\left(q_{l}\right)=\frac{1}{\beta-2}\left(q_{l}+\frac{k r}{\gamma}\right) .
\end{gathered}
$$

Expression (13) tells that the follower's trigger is proportional to the leader's capacity. In other words, if the leader provides more outputs, the follower will enter the market when 
the market demand is larger. Obviously, the leader invests earlier than the follower, so he can enjoy a monopoly profit for some time and occupy a large market share. Only when the follower exercises his option at a high demand level does the firm obtain certain profit.

In addition, (14) means that a higher capacity of leader will bring about a higher capacity of follower, which maybe contradict (12). As a matter of fact, (12) implies that the leader's capacity and the follower's capacity will change inverse on condition that the market demand is fixed. The one invested earlier occupies a larger market share and leaves a smaller share to the follower, so the follower can only enter the market with little output. However, the stochastic market demand makes influence not only on the leader's capacity but also on the follower's and thus brings about the follower's capacity increase along with the leader's eventually.

3.2. The Dominant Leader. In the competitive game, the leader $l$ must consider his rival $f$ 's possible investment strategy. Furthermore, the leader knows that the follower will choose to enter the market when the demand level is $X_{f}^{*}\left(q_{l}\right)$ if the leader chooses $q_{l}$. There are two possibilities for the follower. One is to take action after the leader and thus results in sequential equilibrium; the other is to invest as soon as the leader does and thus results in simultaneous equilibrium. Therefore, if the leader wants to dominate the game, he must stop his rival investing earlier than himself. Suppose that the initial demand level is $X$. To let the selected capacity prevent the competition of the follower successfully, there must be $X_{f}^{*}\left(q_{l}\right)>X$ since the follower must invest after the leader. Denote the solution of $X_{f}^{*}\left(q_{l}\right)=X$ as $\bar{q}_{l}$ and substitute (13) into this expression; we obtain the following proposition.

Proposition 1. To let the rival enter the market later than the firm himself, he can choose a capacity larger than a threshold $\bar{q}_{l}$ to prevent his competitor, where $\bar{q}_{l}$ satisfies

$$
\bar{q}_{l}=\frac{X r(\beta-2)}{\beta \gamma(r-\mu)}-\frac{k r}{\gamma} .
$$

Furthermore, if one firm chooses a capacity lower than $\bar{q}_{l}$, that is, $q_{l} \leq \bar{q}_{l}$, his competitor will enter the market immediately.

Equation (15) says that there must be a larger leader capacity to prevent his rival's action when facing with higher marked demand. If the firm prevents successfully, the rival will then take action at some time later. Let $X_{l d}^{*}(t)$ and $T_{l d}^{*}$ denote the leader's optimal trigger and optimal investment timing, respectively. If the initial state level $X(t)$ is lower than $X_{l d}^{*}(t)$, the leader can enter the market when $T_{l d}^{*}$ is reached. Obviously, there must be $T_{f}^{*}>T_{l d}^{*}$. The value function of the dominant leader $L_{l d}\left(X, q_{l}\right)$ is

$$
\begin{gathered}
L_{l d}\left(X, q_{l}\right)=\max _{T_{l d}^{*}} E_{t}\left\{\int_{T_{l d}^{*}}^{T_{f}^{*}}\left[X(s)-\gamma q_{l}\right] e^{-r(s-t)} q_{l} d s\right. \\
-k q_{l} e^{-r\left(T_{l d}^{*}-t\right)}
\end{gathered}
$$

$$
\begin{aligned}
+\int_{T_{f}^{*}}^{\infty}\left[X(s)-\gamma\left(q_{l}+q_{f}\right)\right] \\
\left.\times q_{l} e^{-r(s-t)} d s\right\} .
\end{aligned}
$$

In the above equation, the first part, denoted by $L_{l d}^{(1)}\left(X, q_{l}\right)$, indicates the monopoly value enjoyed by the leader before the follower exercises his option. The remaining part, denoted by $L_{l d}^{(2)}\left(X, q_{l}\right)$, refers to the duopoly value after the follower's action. In this case, $L_{l d}^{(1)}\left(X, q_{l}\right)$ satisfies the following valuematching and smooth-pasting conditions:

$$
\begin{gathered}
L_{l d}^{(1)}\left(X_{l d}^{*}\right)=\frac{X_{l d}^{*} q_{l}}{r-\mu}-\frac{\gamma q_{l}^{2}}{r}-k q_{l}, \\
\frac{\partial L_{l d}^{(1)}\left(X_{l d}^{*}\right)}{\partial X}=\frac{q_{l}}{r-\mu} .
\end{gathered}
$$

At the follower's threshold $X_{f}^{*}$, however, the value function meets with

$$
L_{l d}^{(1)}\left(X_{f}^{*}\right)=\frac{X_{f}^{*} q_{l}}{r-\mu}-\frac{\gamma q_{l}\left(q_{l}+q_{f}\right)}{r}-k q_{l} .
$$

Solving the partial differential equation like (4) subject to these above constraints, we derive the expression of $L_{l d}^{(1)}\left(X, q_{l}\right)$ and the investment threshold of the dominant leader

$$
X_{l d}^{*}\left(q_{l}\right)=\frac{\beta(r-\mu)}{\beta-1}\left(\frac{\gamma}{r} q_{l}+k\right) .
$$

By Ito's Lemma and the expression of $(16), L_{l d}^{(2)}\left(X, q_{l}\right)$ can be arranged as

$$
\begin{gathered}
\frac{1}{2} \sigma^{2} X^{2} \frac{\partial^{2} L_{l d}^{(2)}(X)}{\partial X^{2}}+\mu X \frac{\partial L_{l d}^{(2)}(X)}{\partial X}-r L_{l d}^{(2)}(X) \\
+\left(X-\gamma q_{l}\right) q_{l}=0 .
\end{gathered}
$$

Given that the negative effect of the follower's option exercise on leader's payoff is $-\gamma q_{l} q_{f}$, it should be subject to the following condition:

$$
L_{l d}^{(2)}\left(X_{f}^{*}\right)=\frac{-\gamma q_{l} q_{f}}{r}
$$

Solving (20) subject to the above condition yields the value function of $L_{l d}^{(2)}\left(X, q_{l}\right)$. 
Summing up the derived $L_{l d}^{(1)}\left(X, q_{l}\right)$ and $L_{l d}^{(2)}\left(X, q_{l}\right)$, the resultant value function is

$$
\begin{aligned}
& L_{l d}\left(X, q_{l}\right) \\
& = \begin{cases}\frac{q_{l}}{\beta-1}\left(\frac{\gamma q_{l}}{r}+k\right)\left(\frac{X}{X_{l d}^{*}}\right)^{\beta} & \text { if } X<X_{l d}^{*}\left(q_{l}\right), \\
-\frac{\gamma q_{l} q_{f}}{r}\left(\frac{X}{X_{l d}^{*}}\right)^{\beta}, & \text { if } X_{l d}^{*}\left(q_{l}\right) \leq X<X_{f}^{*}\left(q_{l}\right), \\
\frac{X q_{l}}{r-\mu}-\frac{\gamma q_{l}^{2}}{r}-k q_{l} & \text { if } X \geq X_{f}^{*}\left(q_{l}\right) . \\
-\frac{\gamma q_{l} q_{f}}{r}\left(\frac{X}{X_{l}^{*}}\right)^{\beta}, & \gamma q_{l}-\frac{\gamma q_{l}\left(q_{l}+q_{f}\right)}{r}-k q_{l},\end{cases}
\end{aligned}
$$

The value function of the dominant leader is composed by three parts. Before the leader enters the market, he holds an American option to enter preferentially. At the time the leader has taken action and the follower does not exercise his option, the leader enjoys a monopoly profit. After the follower invests, the leader value is the net present value of the payoff.

From (16), the intrinsic value of the dominant leader is

$$
W_{l d}\left(X, q_{l}\right)=\max _{q_{l d}^{*}}\left\{\frac{X q_{l}}{r-\mu}-\frac{\gamma q_{l}^{2}}{r}-k q_{l}-\frac{\gamma q_{l} q_{f}}{r}\left(\frac{X}{X_{f}^{*}}\right)^{\beta}\right\} \text {. }
$$

To maximize this value, the optimal capacity $q_{l d}^{*}$ must satisfy the following first order condition

$$
\begin{aligned}
\frac{X}{r-\mu} & -\frac{2 \gamma q_{l d}^{*}}{r}-k \\
& =\frac{\gamma}{r}\left(\frac{X}{X_{f}^{*}}\right)^{\beta}\left[q_{f}+\frac{q_{l d}^{*}}{\beta-2}-\beta q_{l d}^{*} q_{f}^{*} \cdot \frac{\partial X_{f}^{*}}{\partial q_{l d}^{*}} X_{f}^{*}\right] .
\end{aligned}
$$

At the investment moment, $X=X_{l d}^{*}$. Substituting (13) and (14) into the above equation, we obtain

$$
\frac{X_{l d}^{*}}{r-\mu}-\frac{2 \gamma q_{l d}^{*}}{r}-k=\frac{\gamma}{(\beta-2) r}\left(\frac{X_{l d}^{*}}{X_{f}^{*}}\right)^{\beta}\left(2 q_{l d}^{*}+\frac{k r}{\gamma}-\beta q_{l d}^{*}\right) \text {. }
$$

Solving (25), we get the following proposition.

Proposition 2. When one firm is dominating the other in a duopoly market under uncertainty, the two firms will choose their optimal investment triggers and capacities with the forms

$$
\begin{gathered}
X_{l d}^{*}=\frac{\beta k(r-\mu)}{\beta-2}, \quad q_{l d}^{*}=\frac{k r}{(\beta-2) \gamma}, \\
X_{f}^{*}=\frac{(\beta-1)(r-\mu) \beta k}{(\beta-2)^{2}}, \quad q_{f}^{*}=\frac{(\beta-1) k r}{(\beta-2)^{2} \gamma} .
\end{gathered}
$$

3.3. The Preemptive Leader. In this scenario, each firm may be prone to be a leader, so the leadership is determined by their strategic interaction. If the two firms enter the market at the same time, the equilibrium is not a sequential one but a simultaneous one. To avoid the simultaneous investment, suppose that the leader is decided by coin-toss method; then each firm has half of the possibility to be a leader. After the leader takes action, he will enjoy a monopoly profit before the follower enters the game. If the initial state level $X$ is low and $X \leq X_{f}^{*}$, the value function of the preemptive leader can be expressed as

$$
\begin{aligned}
L_{l p}\left(X, q_{l}\right)=E_{t} & \left\{\int_{T_{l p}}^{T_{f}^{*}}\left[X(s)-\gamma q_{l}\right] e^{-r(s-t)} q_{l} d s-k q_{l} e^{-r\left(T_{l p}-t\right)}\right. \\
& \left.+\int_{T_{f}^{*}}^{\infty}\left[X(s)-\gamma\left(q_{l}+q_{f}\right)\right] q_{l} e^{-r(s-t)} d s\right\},
\end{aligned}
$$

where $T_{l p}$ denotes the investment timing of the preemptive leader. From (27), $L_{l p}(X)$ meets with the following valuematching condition:

$$
L_{l p}\left(X_{f}^{*}\right)=\frac{X_{f}^{*} q_{l}}{r-\mu}-\frac{\gamma q_{l}\left(q_{l}+q_{f}\right)}{r}-k q_{l} .
$$

Solving the partial differential equation like (20) subject to the above constraint, we obtain the value function of the preemptive leader

$$
L_{l p}\left(X, q_{l}\right)=\left\{\begin{array}{cc}
\frac{X q_{l}}{r-\mu}-\frac{\gamma q_{l}^{2}}{r}-k q_{l} \\
-\frac{\gamma q_{l} q_{f}}{r}\left(\frac{X}{X_{l}^{*}}\right)^{\beta}, & \text { if } X<X_{f}^{*}\left(q_{l}\right), \\
\frac{X q_{l}}{r-\mu}-\frac{\gamma q_{l}\left(q_{l}+q_{f}\right)}{r} & \\
-k q_{l}, & \text { if } X \geq X_{f}^{*}\left(q_{l}\right) .
\end{array}\right.
$$

Comparing (29) and (22), we find that the value function of the preemptive leader is more complex than that of the dominant one. At the time the follower enters, the value function of the leader is not continuous. This is because the entrance of the follower will bring about negative impact on the leader.

For the preemptive leader, his optimal capacity is also determined by the maximization of his intrinsic value; that is,

$$
W_{l p}\left(X, q_{l}\right)=\max _{q_{l p}^{*}}\left[\frac{X q_{l}}{r-\mu}-\frac{\gamma q_{l}^{2}}{r}-k q_{l}-\frac{\gamma q_{l} q_{f}}{r}\left(\frac{X}{X_{f}^{*}}\right)^{\beta}\right] .
$$

Taking the first derivative on (30) with respect to $q_{l}$, the capacity of the preemptive leader $q_{l p}^{*}$ meets with

$$
\frac{X}{r-\mu}=\frac{\gamma}{r}\left(2 q_{l p}^{*}+q_{f}^{*}+\frac{q_{l p}^{*}}{\beta-2}\right)+k .
$$


Substituting (14) into the above equation, we obtain

$$
q_{l p}^{*}(X)=\frac{r}{2 \gamma}\left[\frac{X(\beta-2)}{(r-\mu)(\beta-1)}-k\right] .
$$

Hence, the optimal capacity is positive proportional to the total market demand.

Now consider the investment strategy of the preemptive leader. If one firm decides to provide $q_{l}$ unit of output, he faces two choices. One is to compete the leadership in the game and obtain the payoff $L_{l d}\left(X, q_{l}\right)$; the other is to be a follower and get the payoff $F\left(X, q_{l}\right)$. When the market demand is low, the leader value in (29) will be negative and lower than the follower's strictly, and preemptive competition will not happen. Only when the preemptive leader's value is larger than the follower's the preemptive action will occur. Therefore, the function $L_{l d}\left(X, q_{l}\right)$ is defined in the range $\{X \geq$ $\left.0: L_{l d}\left(X, q_{l}\right) \geq F\left(X, q_{l}\right)\right\} . X_{l p}$ must be the solution of the equation $L_{l d}\left(X, q_{l}\right)=F\left(X, q_{l}\right)$; that is,

$$
\begin{gathered}
\frac{X_{l p} q_{l p}^{*}}{r-\mu}-\frac{\gamma}{r} q_{l p}^{* 2}-k q_{l p}^{*}-\frac{\gamma}{r} q_{l p}^{*} q_{f}^{*}\left(\frac{X_{l p}}{X_{f}^{*}}\right)^{\beta} \\
=\frac{q_{l p}^{*}}{\beta-1}\left[\frac{\gamma}{r}\left(q_{l p}^{*}+q_{f}^{*}\right)+k\right]\left(\frac{X_{l p}}{X_{f}^{*}}\right)^{\beta} .
\end{gathered}
$$

Substituting (13) and (14) into the above equation and combining (32), we obtain the following proposition.

Proposition 3. If two firms preempt the game in a duopoly market under uncertainty, the optimal capacity of the preemptive leader $q_{l p}^{*}$ is the solution of

$$
\beta q_{l p}^{*}+\frac{k r}{\gamma}=2\left(q_{l p}^{*}+\frac{k r}{\gamma}\right)\left[\frac{(\beta-1)\left(2 q_{l p}^{*}+k r / \gamma\right)}{\beta\left(q_{l p}^{*}+k r / \gamma\right)}\right]^{\beta}
$$

and the solution must exist and be unique. Furthermore, the investment threshold of the preemptive leader $X_{l p}$ can be expressed as

$$
X_{l p}=\frac{(r-\mu)(\beta-1) r}{\beta-2}\left[\frac{2 \gamma q_{l p}^{*}}{r}+k\right] .
$$

The follower's trigger and optimal capacity satisfy

$$
X_{f}^{*}=\frac{\gamma \beta(r-\mu)}{r(\beta-2)}\left(q_{l p}^{*}+\frac{k r}{\gamma}\right), \quad q_{f}^{*}=\frac{1}{\beta-2}\left(q_{l p}^{*}+\frac{k r}{\gamma}\right) \text {. }
$$

Proof. Simplifying (33), we can obtain the following equation:

$$
\frac{X_{l p}}{r-\mu}-\frac{\gamma q_{l p}^{*}}{r}-k=\frac{2 \gamma}{(\beta-2) r}\left(\frac{X_{l p}}{X_{f}^{*}}\right)^{\beta}\left(q_{l p}^{*}+\frac{k r}{\gamma}\right) .
$$

Substituting (32) into the above equation, we get (34). Now prove the existence and uniqueness of the preemptive capacity. Suppose that

$$
(\beta-1)\left(2 q_{l p}^{*}+\frac{k r}{\gamma}\right)=z \beta\left(q_{l p}^{*}+\frac{k r}{\gamma}\right)
$$

where $z$ is a parameter to be determined. Therefore,

$$
\beta q_{l p}^{*}+\frac{k r}{\gamma}=2 z^{\beta}\left(q_{l p}^{*}+\frac{k r}{\gamma}\right)
$$

Simplifying the above two equations, we get

$$
\begin{gathered}
q_{l p}^{*}=\frac{\beta z-\beta+1}{\beta-1-\beta z} \frac{k r}{\gamma}, \\
q_{l p}^{*}=\frac{2 z^{\beta}-1}{\beta-2 z^{\beta}} \frac{k r}{\gamma} .
\end{gathered}
$$

These two optimal capacities must be identical to each other. After combining the above two equations, we have

$$
2 z^{\beta}-\beta z+\beta-2=0
$$

Obviously, one solution is 1 ; that is, $q_{l p}^{*}=k r / \gamma(\beta-2)$. After calculation, we derive $X_{l p}=X_{f}^{*}$. The expression means that the preemptive leader and the follower will enter the market simultaneously, which contradicts the definition of the preemptive trigger. Hence, $z=1$ is ignored. Consider the existence and uniqueness of the other solution in the range $(0,1)$. Suppose that $f(z)=2 z^{\beta}-\beta z+\beta-2$; then $f^{\prime \prime}(z)=$ $2 \beta(\beta-1)>0$, from which we know that $f(z)$ is convex. Meanwhile, $f(0)=\beta-2>0, f(1)=0, f^{\prime}(0)=-\beta<0$, $f^{\prime}(1)=\beta>0$. Consequently, there must be one unique solution $z^{*} \in(0,1)$ such that $f(z)=0$. Thus, the optimal capacity has the form

$$
q_{l p}^{*}=\frac{\beta z^{*}-\beta+1}{\beta-1-\beta z^{*}} \frac{k r}{\gamma}
$$

and the capacity is unique. After the optimal capacity of the preemptive leader is determined, the investment triggers of the leader and the follower and the follower's capacity can be determined.

Although there are not explicit expressions for the investment triggers and their capacities in the preemptive case, we can see that each person's trigger is positive to his capacity. Moreover, the higher the capacity of the leader is, the higher the capacity of the follower is. These conclusions are the same as that in the dominant case.

When the initial state level is larger than the follower trigger, two firms will take action at once. Therefore, when $X>X_{f}^{*}$, they will enter the market immediately with their optimal capacities that maximize the intrinsic value $W(X)$, where

$$
W(X)=\max _{q^{*}}\left\{\frac{X q}{r-\mu}-\frac{2 \gamma q^{2}}{r}-k q\right\} .
$$

After solving (43), we can derive the optimal capacity. The following proposition gives the investment strategy in simultaneous equilibrium.

Proposition 4. If the initial market demand level is high, then two firms will enter the market at the same time. 
The optimal capacity and the market demand have the following correlation:

$$
q^{*}(X)=\frac{r}{4 \gamma}\left(\frac{X}{r-\mu}-k\right) .
$$

Furthermore, this optimal capacity must surpass $k r(\beta-$ $1) /[2 \gamma(\beta-2)]$.

What should be mentioned is that there still exists one special situation, in which two firms collude with each other. In this case, they combine into one organization and enter the market simultaneously.

\section{Comparative Static}

Consider the dominant case. In this case, the optimal investment triggers and capacities satisfy (26). For these investment thresholds, we find that

$$
\begin{gathered}
\frac{\partial X_{l d}^{*}}{\partial \sigma}=-2(r-\mu) k \frac{\partial \beta}{\partial \sigma}>0, \\
\frac{\partial X_{f}^{*}}{\partial \sigma}=-k(r-\mu) \frac{(3 \beta-2)}{(\beta-2)^{3}} \frac{\partial \beta}{\partial \sigma}>0 .
\end{gathered}
$$

The above two equations tell that each firm will postpone his investment action when facing greater uncertainty whatever role he is. This is because that greater uncertainty means greater risk during investment. Thus, they will wait and look for better opportunity.

Furthermore,

$$
\frac{\partial\left(X_{f}^{*} / X_{l d}^{*}\right)}{\partial \sigma}=-\frac{1}{(\beta-2)^{2}} \cdot \frac{\partial \beta}{\partial \sigma}>0,
$$

which says that the difference between the trigger of the leader and that of the follower will be larger in the face of increasing uncertainty. In other words, if there is greater uncertainty in the market, both firms will delay investment and the delayed margin of the follower will surpass that of the leader. This is because the dominant leader will enjoy more monopoly profit if he takes action earlier and will not be reluctant to postpone investment.

Comparing these two optimal capacities, we find

$$
\begin{aligned}
& \frac{\partial q_{l d}^{*}}{\partial \sigma}=-\frac{k r}{\gamma(\beta-2)^{2}} \frac{\partial \beta}{\partial \sigma}>0, \\
& \frac{\partial q_{f}^{*}}{\partial \sigma}=-\frac{\beta k r}{\gamma(\beta-2)^{3}} \frac{\partial \beta}{\partial \sigma}>0 .
\end{aligned}
$$

The above two equations show that two optimal capacities will increase along with the increase of uncertainty. In other words, when there is more uncertainty in the market, two firms will be prone to provide more outputs. One primary reason is that two firms will delay investment under greater uncertainty. Therefore, they will take action at a larger demand level with more commodities.
In addition,

$$
\begin{gathered}
\frac{q_{f}^{*}}{q_{l d}^{*}}=\frac{\beta-1}{\beta-2}>1, \\
\frac{\partial\left(q_{f}^{*} / q_{l d}^{*}\right)}{\partial \sigma}=-\frac{1}{\gamma(\beta-2)^{2}} \frac{\partial \beta}{\partial \sigma}>0 .
\end{gathered}
$$

From (48), we know that the optimal capacity of the follower is larger than that of the dominant leader. However in A. Sadanand and V. Sadanand [19] and Maggi [20], they draw an opposite conclusion. In their opinion, if two firms compete for the leadership, the one with a larger capacity can obtain the leadership successfully, which is contrary to the investment behavior in reality. For example, in the hot spot industry, a company named T-mobile entered the WiFi services market with a smaller capacity than its competitor named Cometa Network. After competition, T-mobile succeeded and drove its rival out of the market although the capacity of Cometa Network was three times as T-mobile's. This event indicates that the firm with a smaller capacity can preempt the leadership and confirms our conclusion. In other words, if one firm chooses a larger capacity, the firm has given up the competition of the leadership and destines to fail in the game since it will be turned out of the market by its rival through smaller capacities. In addition, the conclusion can be explained through their investment thresholds. For these two firms, the investment trigger of the follower is larger than that of the leader, which means that the follower will enter the market in a larger market demand state and thus more commodities will be provided.

Furthermore, although the leader takes action earlier than the follower, the payoff of the leader is lower than that of the follower because of the smaller capacity of the former. Therefore, the one invested later will obtain more profit. It does not mean each firm will be prone to be a follower. The reason is as follows. Before the follower enters the market, the leader will obtain a monopoly profit after investment for a period of time. During that time, the leader can also establish brand reputation, develop corporate culture, and advertise to consumers, provide better facilities or services and thus occupy better market position. Let T-mobile be an example, it preempted the market with small scale of wireless hot spot and then provided free Wi-Fi service. Therefore, other companies cannot compete with it by similar service.

Equation (49) tells that both firms will provide more outputs when the uncertainty in the market increases. Moreover, the growth rate of the follower's capacity will exceed that of the leader's. Just as mentioned above, the follower will wait for the coming of a much higher demand state as greater uncertainty exists, so the follower should provide a larger output to satisfy the demand.

Now consider the preemptive case. Since we cannot obtain explicit form of the preemptive trigger from (36), the problem will be analyzed by numerical method, just as listed in Figure 1.

From Figure 1 we know that the conclusions of investment strategies in the preemptive case are similar to the results obtained in the dominant case. Figure 1(a) says that both 


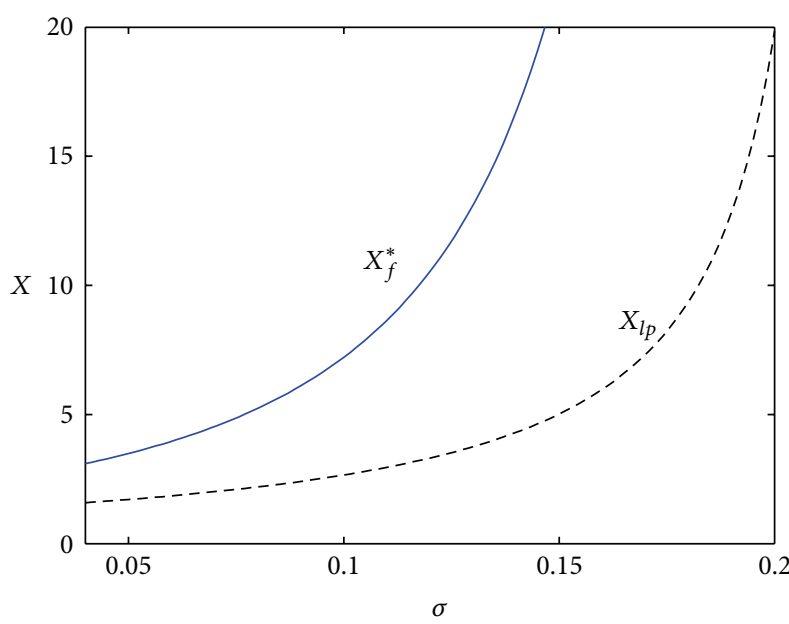

(a) Investment trigger

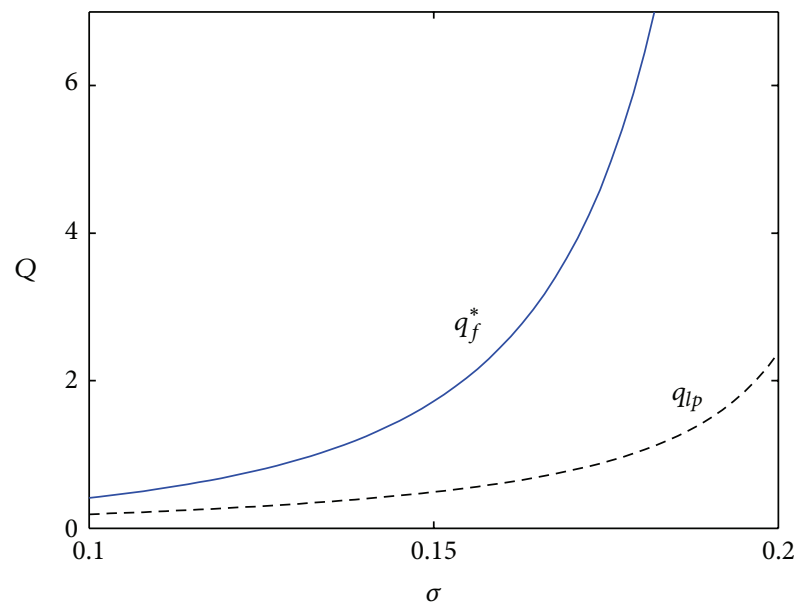

(b) Optimal capacity

FIGURE 1: Investment strategies in the preemptive case. The parameter values are $r=0.05, k=40, \mu=0.001$, and $\gamma=4$.

the preemptive leader and the follower will postpone their investment action when greater uncertainty exists in the market and the postponed time of the leader will not surpass that of the follower. Consider their capacity strategies; Figure 1(b) shows that the leader capacity is lower than the follower capacity. Moreover, both $q_{l p}^{*}$ and $q_{f}^{*}$ increase along with the increase of $\sigma$ and the growth rate of $q_{f}^{*}$ is larger than that of $q_{l p}^{*}$. Therefore, the follower will be prone to enter the market with a larger increased margin of capacity than his rival. These conclusions can be explained by the same reason as in the dominant case.

\section{Conclusion}

In the traditional real option literature, such as Grenadier [6] and Wang and Zhou [10], investment scale is fixed. Firms will only consider their investment timing of entering the market. In this paper, investment scale should be chosen by investors themselves. For any firm, it must consider when to enter the market and how much production to be provided. Moreover, each firm will provide its output by lumpy investment.

In the duopoly market, the leader, whether he is dominant or preemptive in the game, will make great influence on the follower's investment strategy. When facing great uncertainty, two firms will postpone their investment action. Meanwhile, the delayed degree on both investment timing and capacity of the follower will surpass that of the leader. Most important of all, the optimal capacity of the leader will be lower than that of the follower under uncertainty, which is contrary to the conclusion in Stackelberg model under certain environment. In addition, the one with less capacity can compete with his rival successfully. He can obtain monopoly profit and occupy better market position before the entrance of the follower and therefore gain more consumers in the end.

\section{Conflict of Interests}

The authors declare that there is no conflict of interests regarding the publication of this paper.

\section{Acknowledgments}

The authors are grateful to the referees for their helpful and useful comments. This research is partially supported by the Scientific Research Fund of Chongqing Technology and Business University (no. 1351004) and by the Research Fund of School of Finance in Chongqing Technology and Business University (no. 20132011031).

\section{References}

[1] A. K. Dixit and R. S. Pindyck, Investment under Uncertainty, Princeton University Press, Princeton, NJ, USA, 1994.

[2] E. S. Schwartz and L. Trigeorgis, Real Options and Investment under Uncertainty: Classical Readings and Recent Contributions, The MIT Press, Cambridge, Mass, USA, 2001.

[3] R. S. Pindyck, "Irreversible investment, capacity choice, and the value of the firm," The American Economic Review, vol. 78, no. 5, pp. 969-985, 1988.

[4] S. Capozza and Y. Li, "The timing and intensity of investment," The American Economics Review, vol. 84, no. 4, pp. 889-904, 1994.

[5] H. T. J. Smit and L. Trigeorgis, Strategic Investment: Real Options and Games, Princeton University Press, Princeton, NJ, USA, 2004.

[6] S. R. Grenadier, "The strategic exercise of options: development cascades and overbuilding in real estate markets," The Journal of Finance, vol. 51, no. 5, pp. 1653-1679, 1996.

[7] S. R. Grenadier, "Option exercise games: an application to the equilibrium investment strategies of firms," Review of Financial Studies, vol. 15, no. 3, pp. 691-721, 2002. 
[8] Y. Chu and T. F. Sing, "Optimal timing of real estate investment under an asymmetric duopoly," The Journal of Real Estate Finance and Economics, vol. 34, no. 3, pp. 327-345, 2007.

[9] J. J. Kong and Y. K. Kwok, "Real options in strategic investment games between two asymmetric firms," European Journal of Operational Research, vol. 181, no. 2, pp. 967-985, 2007.

[10] K. Wang and Y. Zhou, "Equilibrium real options exercise strategies with multiple players: the case of real estate markets," Real Estate Economics, vol. 34, no. 1, pp. 1-49, 2006.

[11] F. L. Aguerrevere, "Real options, product market competition, and asset returns," The Journal of Finance, vol. 64, no. 2, pp. 957983, 2009.

[12] M. Yang and Q. Zhou, "Real options analysis for efficiency of entry deterrence with excess capacity," System Engineering: Theory \& Practice, vol. 27, no. 10, pp. 63-70, 2007.

[13] T. Dangl, "Investment and capacity choice under uncertain demand," European Journal of Operational Research, vol. 117, no. 3, pp. 415-428, 1999.

[14] R. Novy-Marx, "An equilibrium model of investment under uncertainty," Review of Financial Studies, vol. 20, no. 5, pp. 14611502, 2007.

[15] R. Mason and H. Weeds, "Investment, uncertainty and preemption," International Journal of Industrial Organization, vol. 28, no. 3, pp. 278-287, 2010.

[16] D. Besanko, U. Doraszelski, L. Lu, and M. Satterthwaite, "Lumpy capacity investment and disinvestment dynamics," Operations Research, vol. 58, no. 4, part 2, pp. 1178-1193, 2010.

[17] M. Nishihara and M. Fukushima, "Evaluation of firm's loss due to incomplete information in real investment decision," European Journal of Operational Research, vol. 188, no. 2, pp. 569-585, 2008.

[18] A. Bar-Ilan and W. C. Strange, "The timing and intensity of investment," Journal of Macroeconomics, vol. 21, no. 1, pp. 57-77, 1999.

[19] A. Sadanand and V. Sadanand, "Firm scale and the endogenous timing of entry: a choice between commitment and flexibility," Journal of Economic Theory, vol. 70, no. 2, pp. 516-530, 1996.

[20] G. Maggi, "Endogenous leadership in a new market," Rand Journal of Economics, vol. 27, no. 4, pp. 641-659, 1996. 


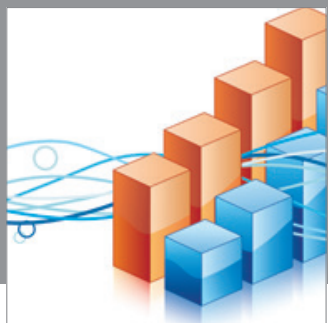

Advances in

Operations Research

mansans

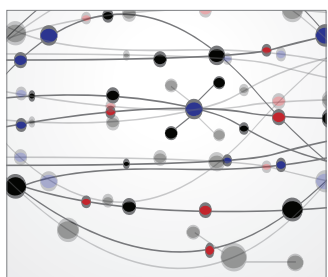

The Scientific World Journal
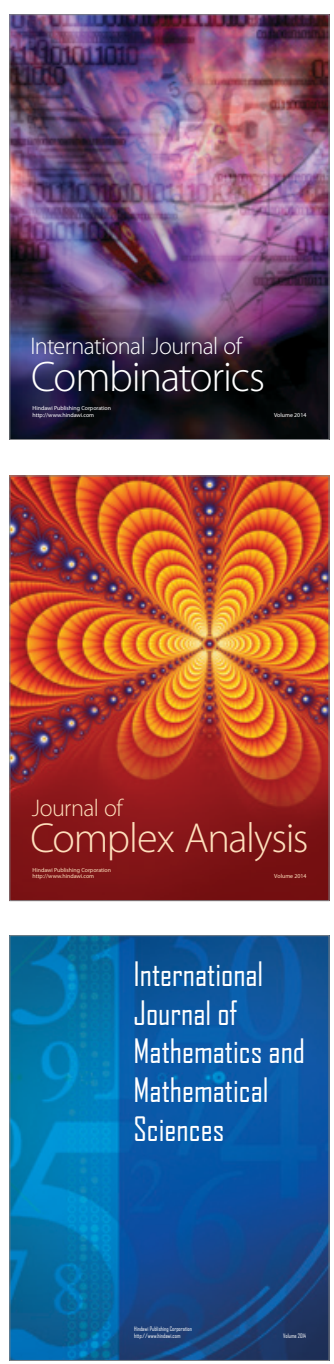
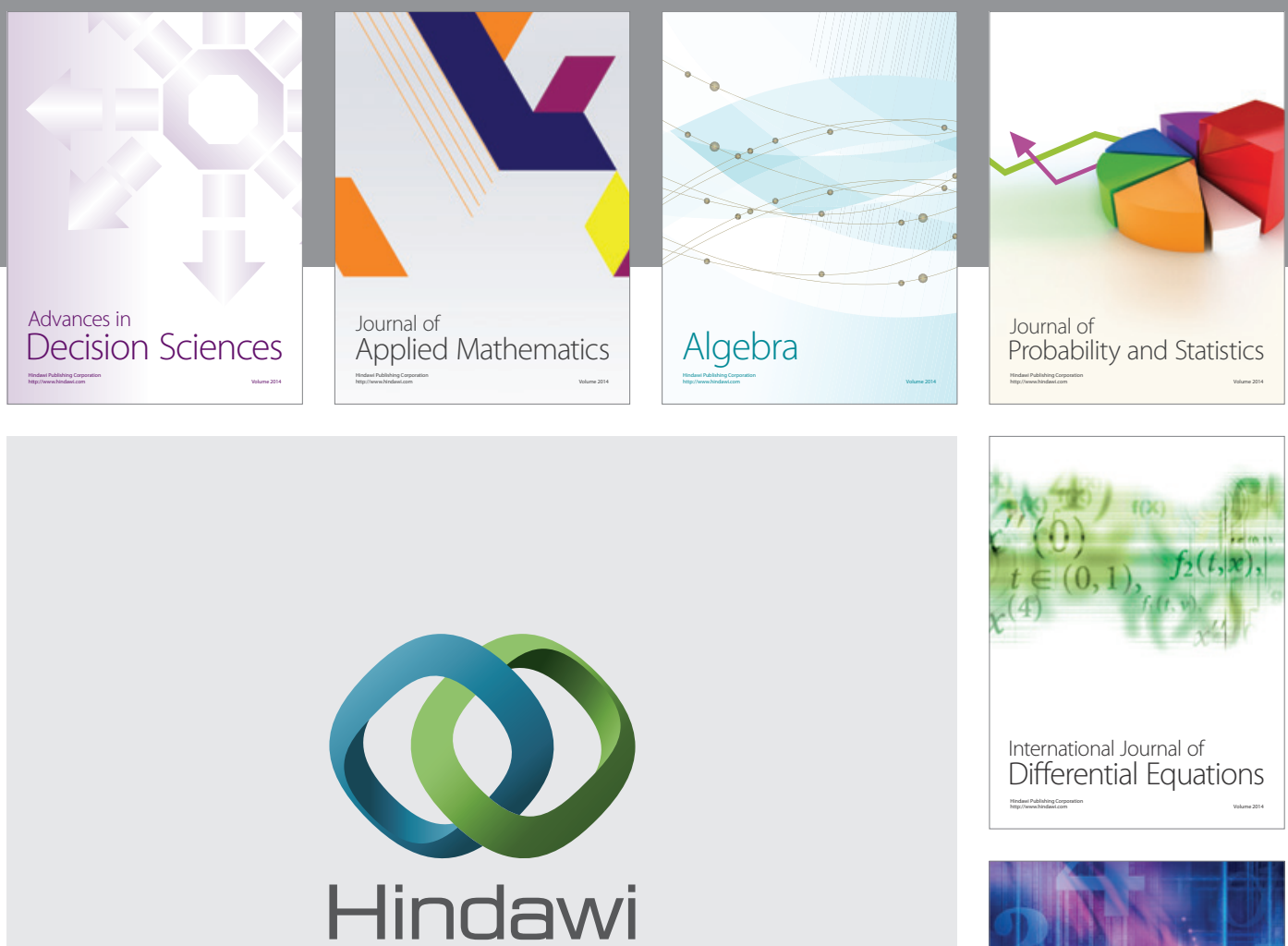

Submit your manuscripts at http://www.hindawi.com
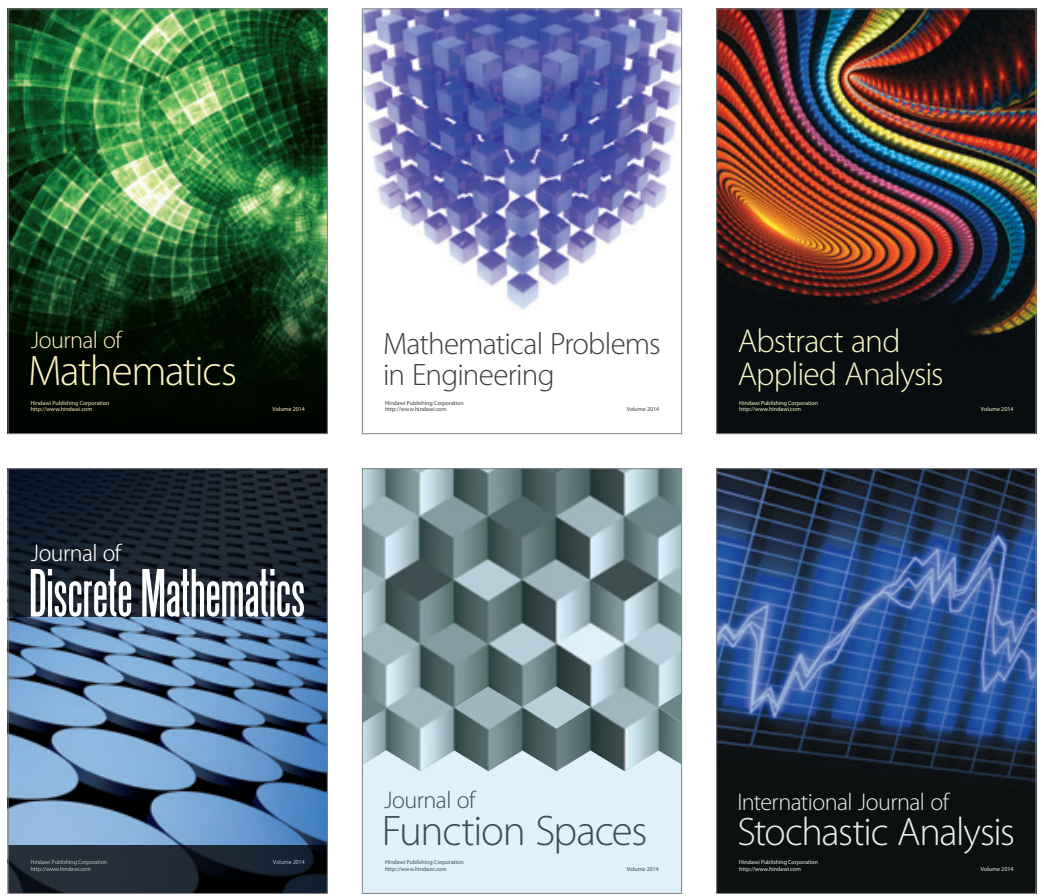

Journal of

Function Spaces

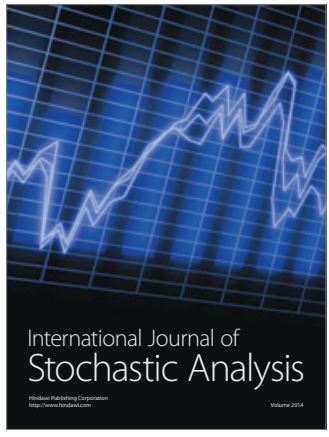

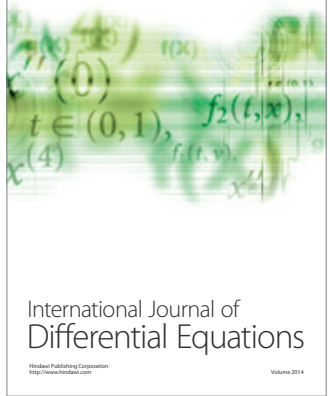
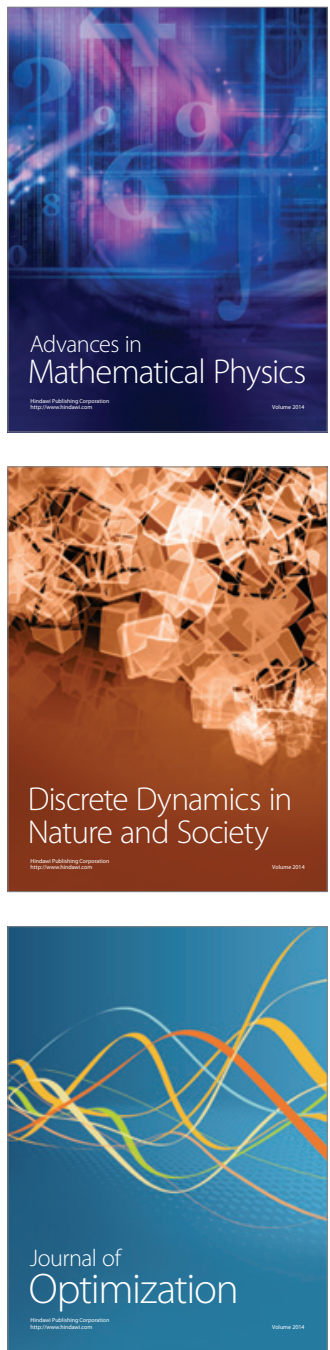